\title{
CARTOGRAFANDO DESEJOS: ETNOGRAFIA VISUAL NOS PONTOS DE PROSTITUIÇÃO FEMININOS EM GOIÂNIA/GO E APARECIDA DE GOIÂNIA/GO
}

\author{
Joab Júnio D. G. da Silva ${ }^{1}$
}

As emoções são partes constitutivas de um trabalho de colorações etnográficas. Não foram poucas as situações em que, ao comentar sobre o trabalho que realizava no mestrado, meus interlocutores advertiam: "Cuidado! As travestis não são de brincadeira..."; "Você está fazendo um trabalho na zona?! Não é perigoso, não?”; “Olha, eu não teria coragem. Por que você não realiza uma entrada diferente?’. Impossível ignorar os efeitos performativos destes e de tantos outros alertas, afinal, já senti meu coração acelerar, as fibras das vestes colarem à pele e as mãos gelarem, perante a perspectiva da entrada e realização do trabalho de campo.

Contudo, torna-se inevitável deixar de refletir sobre o modo com que as noções de "perigo", "risco" e "ameaça" saturam nossas representações sobre prostituição, travestilidades, territórios e temporalidades voltados à mercantilização de serviços sexuais (Silva, 2007). Afinal, qual era o perigo pelo qual deveria me atentar enquanto realizava meu trabalho? $\mathrm{O}$ que um conjunto de práticas fortemente moralizadas e limítrofes poderiam suscitar? Quais os efeitos de trânsitos, mobilidades e derivas sobre as nossas noções de corpo, gênero e sexualidade? Como deveria lidar com a noite e os inúmeros "riscos" e "vicissitudes" a ela associados?

As questões acima elencadas fizeram parte da constelação de problemas que orientaram a escrita da minha dissertação. Os usos e apropriações de territorialidades urbanas via prostituição de pessoas travestis e de mulheres cisgêneras constituíram o objeto que norteou o conjunto das reflexões realizadas no meu trabalho, compondo a paleta de cores deste ensaio visual. Questionando a forma com que o presente nicho do mercado sexual permite compreender a produção de territorialidades e fronteiras urbanas, lancei mão de um relato etnográfico multissituado (Marcus, 1995), recorrendo às derivas urbanas 
(Debord, 2003) enquanto recurso metodológico para produção de dados em campo. O Diário de Campo e os desenhos etnográficos fizeram parte das técnicas utilizadas para compilação e análise dos dados produzidos.

Partindo das anotações realizadas em meu Diário de Campo, ao longo do segundo semestre de 2019 e início de 2020, realizei decalques das observações realizadas em dois pontos de prostituição de rua (Setor Leste Universitário - Goiânia/GO e "Setor dos Motéis" - Aparecida de Goiânia/GO) e dois cinemas adultos localizados em Goiânia/GO (Cine Santa Maria e Cine Apollo Show), Neste sentido, não objetivei construir um relato calcado na máxima malinowskiniana do "eu estive lá”. Pelo contrário, o desenho surgiu como uma necessidade, provocando novos deslocamentos pelas esquinas, encruzilhadas e becos, promovendo assim suturas entre autor e obra. De modo semelhante a Inês Belo Gomes (2016), precisei “desenterrar o desenho", ressignificar a "Escrita” e compreender tal dimensão etnográfica como diálogo, imersão e rememoração.

Os tons aquarelados, saturados em vermelho, roxo e azul, e o uso de traços pontiagudos e angulosos talvez representem o modo com que o processo etnográfico afetou minhas percepções em campo, colocando em jogo, de forma concomitante, o conjunto de prismas construídos sobre corpo, mercado sexual, territórios e temporalidades, afinal, "a imagem e a performance são os elementos constitutivos da ética da prostituição feminina" (Nieto Olivar, 2007:7. tradução minha).

Por meio deste ensaio foi possível cartografar o conjunto de trajetos realizados durante a minha pesquisa, considerando os diálogos travados, situações vivenciadas em campo e tensionamentos experenciados junto às minhas interlocutoras, permitindo assim compreender as formas de apropriação, ressignificação e gestão de territórios voltados à comercialização de serviços sexuais.

Por fim, entendendo a deriva enquanto trânsito, experimentação e investigação do meio urbano (DEBORD, 2003. p. 87) busquei, por um lado, exercitar faculdades de entendimento calcadas no "Ver", "Ouvir" e "Escrever", conforme ensina Roberto Cardoso de Oliveira (1996) e, por outro, cultivar uma sensibilidade etnográfica que nos conduza a estranhamentos, surpresas e acasos em campo (Peirano, 2014). 


\section{REFERÊNCIAS}

DEBORD, Guy. Teoria da deriva. In: BERENSTEIN, Paola Jaques (Org.). Apologia da deriva: escritos situacionistas sobre a cidade. Rio de Janeiro: Casa da Palavra, 2003. pp. 87-91.

GOMES, Inês Belo. "Deixei o desenho enterrado" ou como ressuscitar o grafismo enquanto metodologia antropológica: um caso prático. Cadernos de Arte e Antropologia, Salvador, V. 5, n. 2, pp. 75-90, 2016.

MARCUS, George E. Ethnography in/of the World System: The Emergence of MultiSited Ethnography. Annual Review of Anthropology, Palo Alto, v. 24, pp. 95-117, 1995. Disponível em:

$<$ https://edisciplinas.usp.br/pluginfile.php/1897105/mod_resource/content $/ 1 /$ George $\% 2$ 0Marcus_Etnography\%20in\%20off\%20world.pdf>. Acesso em: 09 dez. 2020.

NIETO OLIVAR, José Miguel. "Dibujando Putas: reflexiones de una experiencia etnográfica com apariciones fenomenológicas". Revista Chilena de Antropología Visual, Santiago, n.10, pp. 54-84. 2007.

OLIVEIRA, Roberto Cardoso de. O trabalho do antropólogo: olhar, ouvir, escrever. Revista de antropologia, São Paulo, v. 39, n. 1, pp. 13-37, 1996.

PEIRANO, Marisa. Etnografia não é método. Horizontes Antropológicos, Porto Alegre, ano 20, n. 42, p. 377-391, 2014.

SILVA, Larissa Maués Pelúcio. Nos nervos, na carne, na pele: uma etnografia sobre prostituição travesti e o modelo preventivo de aids. 2007. 313 f. Tese (Doutorado em Ciências Sociais) - Centro de Educação e Ciências Humanas, Universidade Federal de São Carlos, São Carlos, 2007.

Recebido: 26/01/2021

Aprovado: 02/06/2021 
Imagem 1. "Sob a luz vermelha" Diário de campo do autor. 2020.
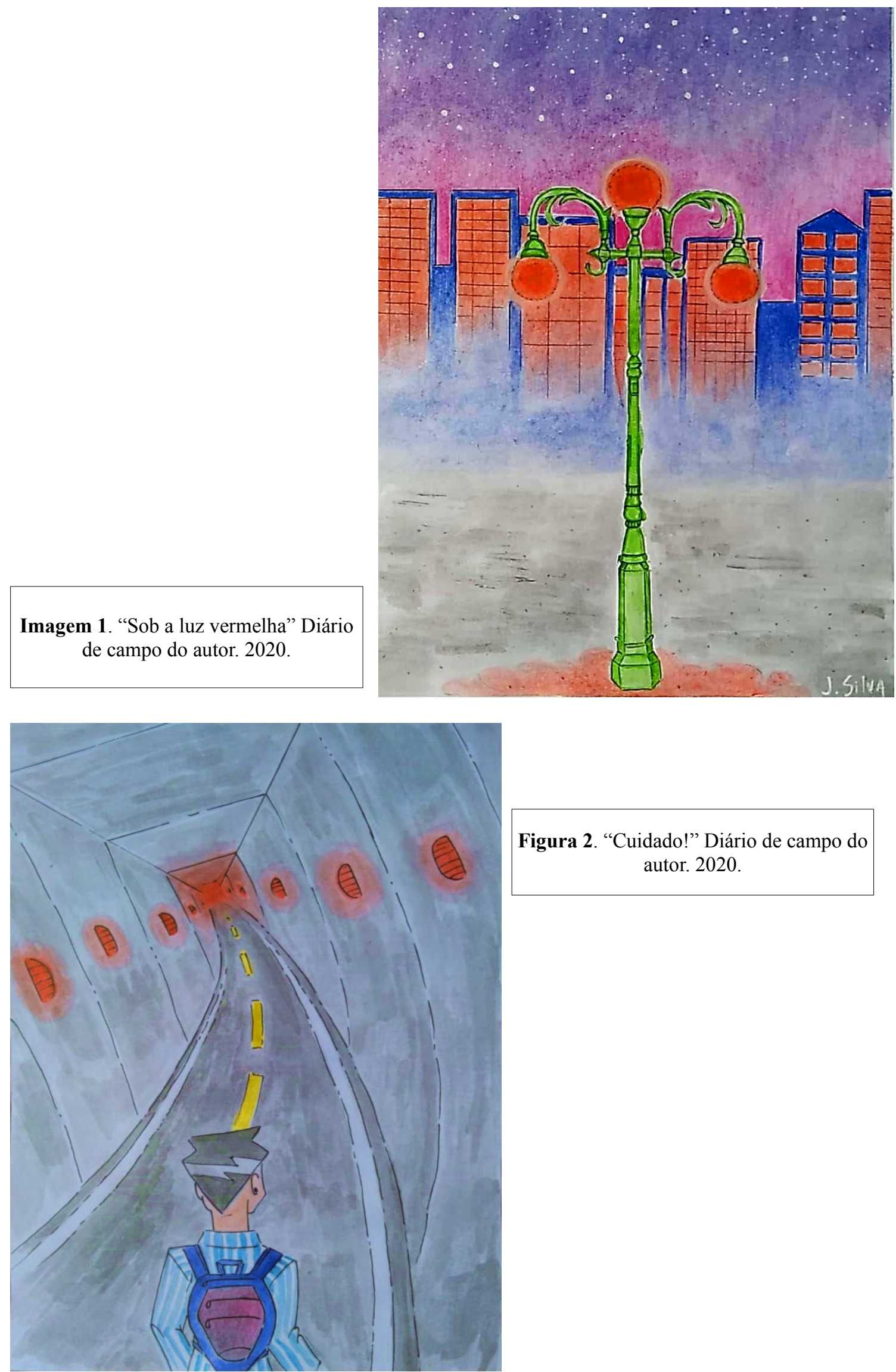

Figura 2. "Cuidado!" Diário de campo do autor. 2020.

Iluminuras, Porto Alegre, v. 22, n. 56, p. 321-329, junho, 2021. 


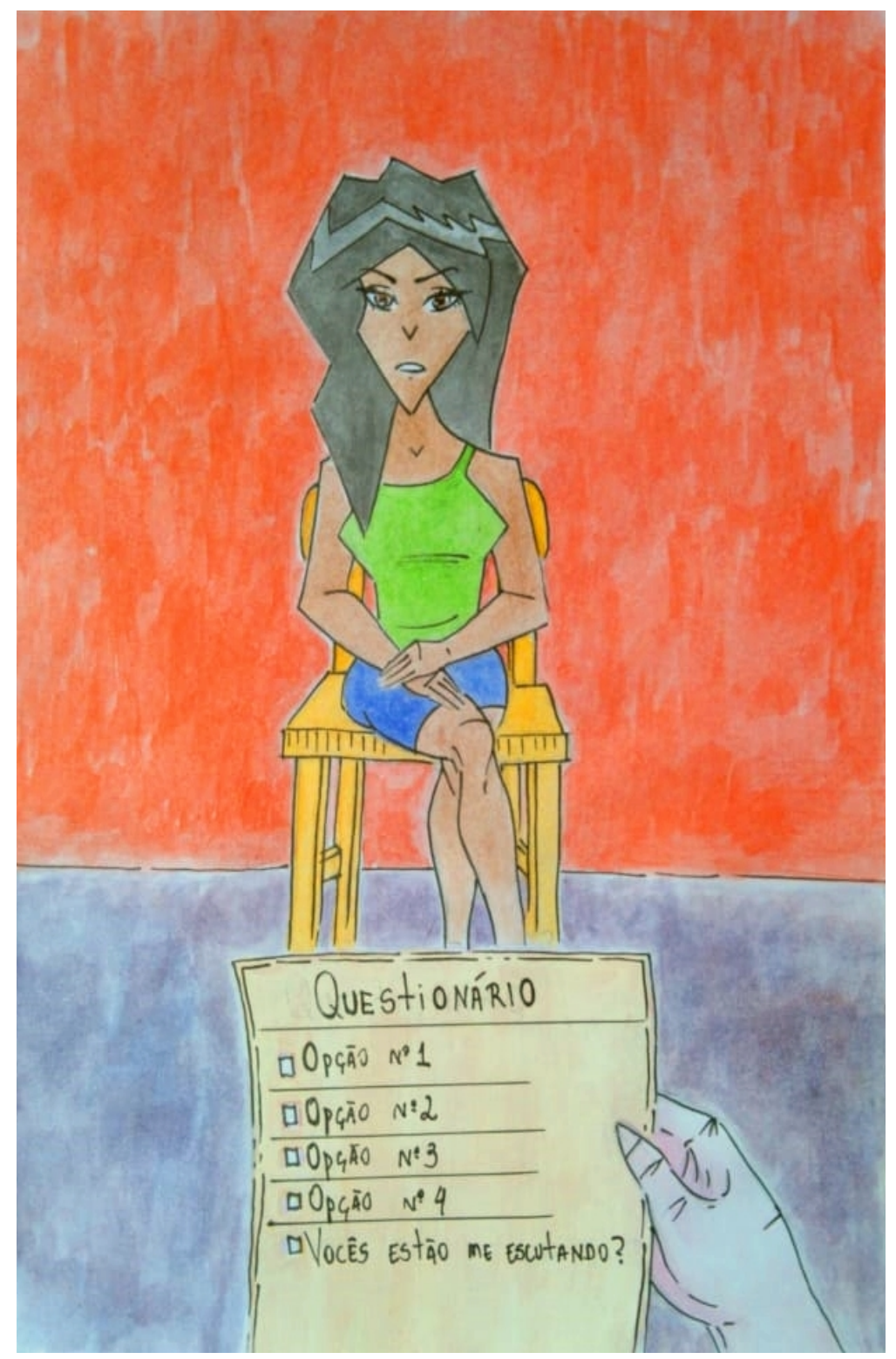

Figura 3. "Das armadilhas de uma ciência cisgênera: sua identidade cabe no meu questionário?" Diário de campo do autor. 2020

Figura 4. "Nós somos os ratinhos de laboratório da UFG! Tensionamentos etnográficos em campo". Diário de campo do autor. 2020 .

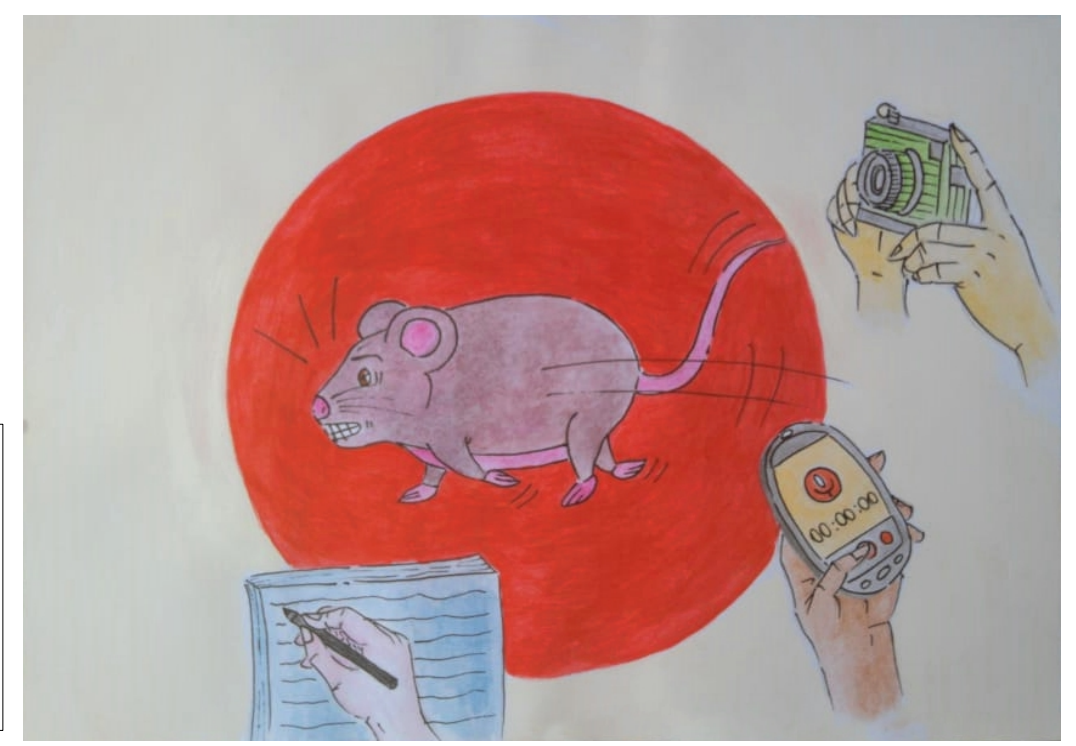

Iluminuras, Porto Alegre, v. 22, n. 56, p. 321-329, junho, 2021. 


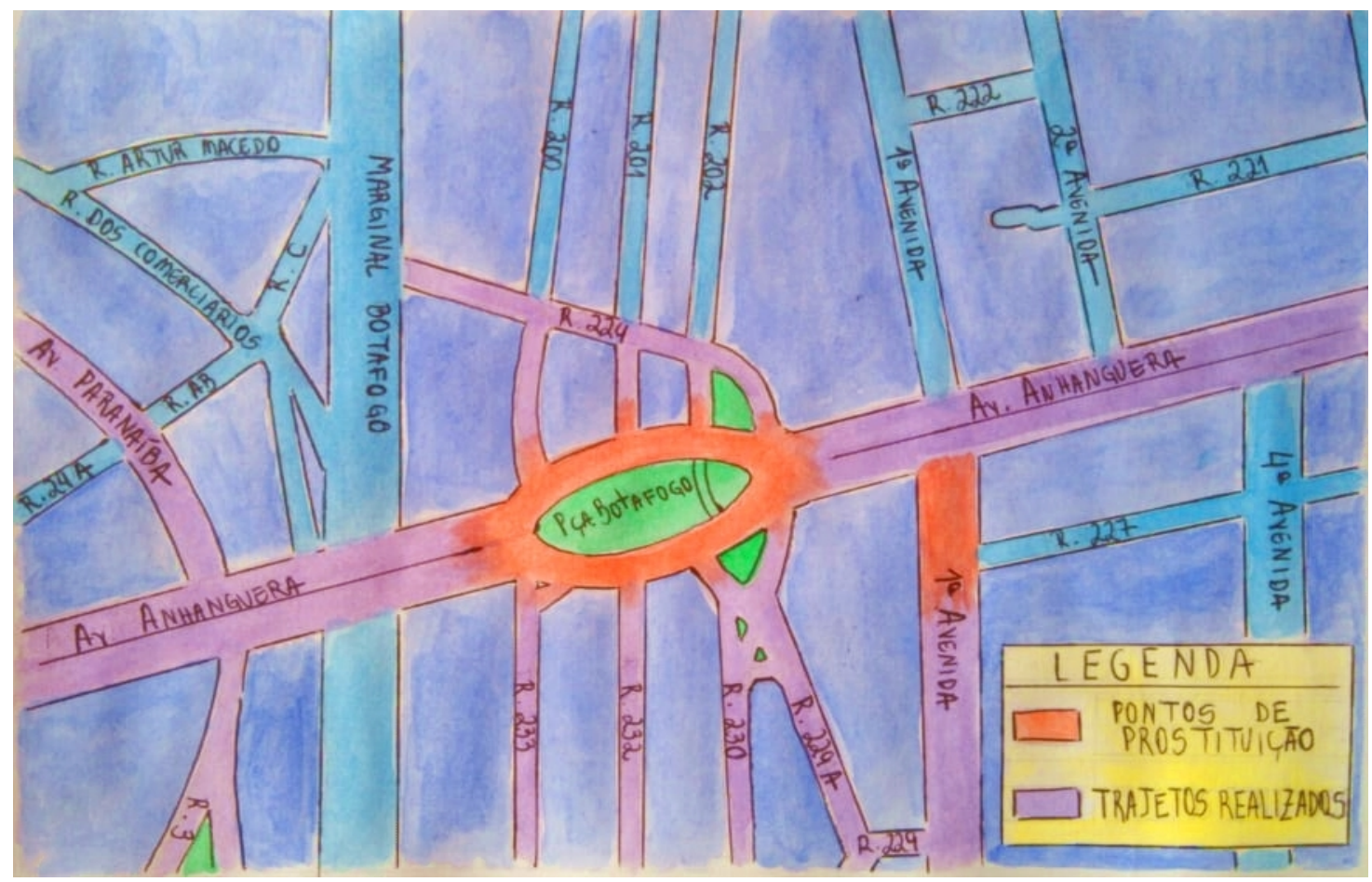

Mapa 1 - Setor Leste Universitário, Goiânia/GO.

Representação cartográfica dos pontos de prostituição de pessoas travestis (vermelho), trajetos realizados (roxo), ruas adjacentes (azul-claro), espaços residenciais (azul-escuro) e áreas arborizadas (verde). Diário de campo do autor. 2020.

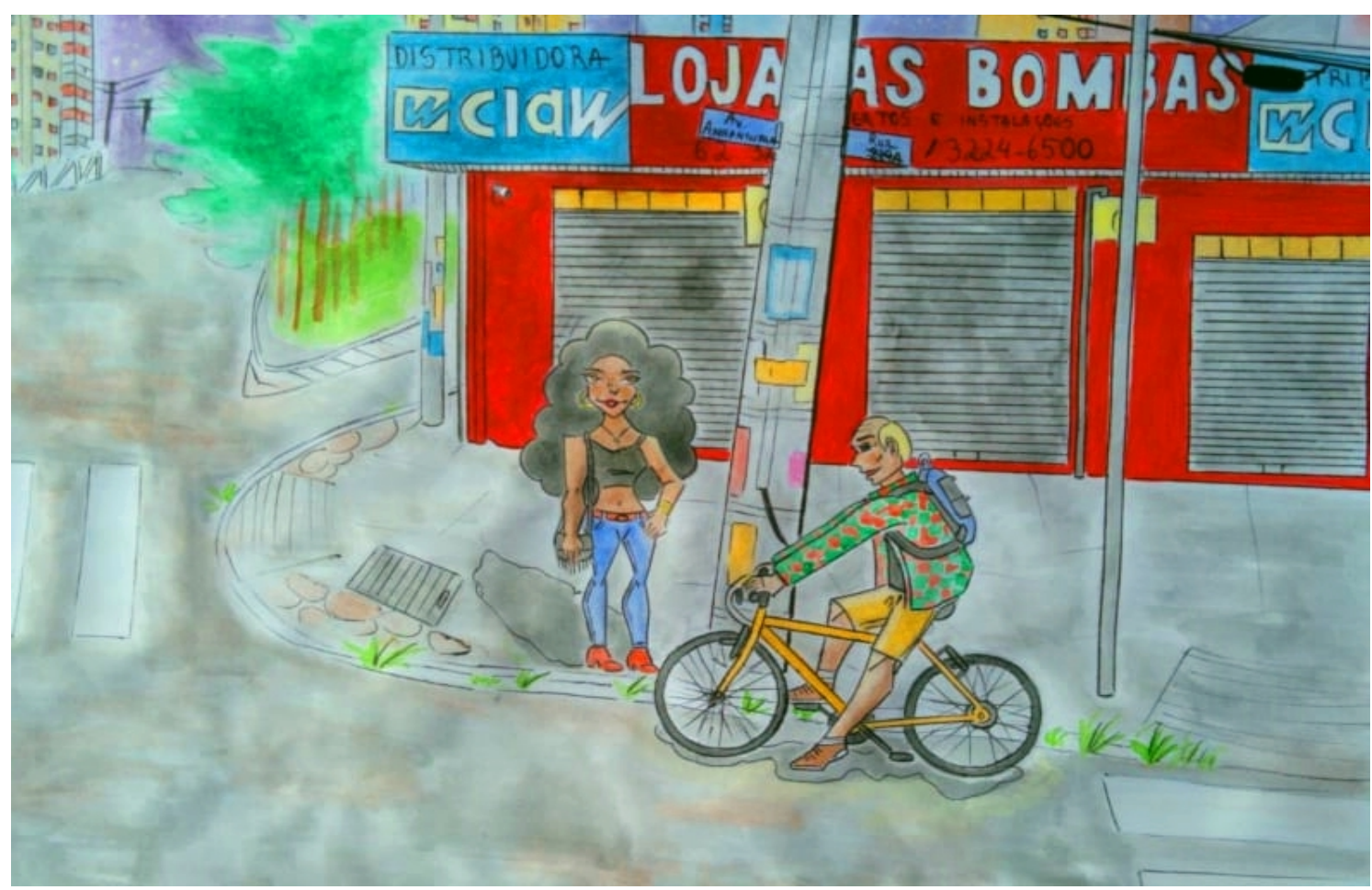

Figura 5. "Profissional abordada por cliente". Praça Botafogo, Setor Leste Universitário, Goiânia/GO. Diário de campo do autor. Noite. 2019.

Iluminuras, Porto Alegre, v. 22, n. 56, p. 321-329, junho, 2021. 


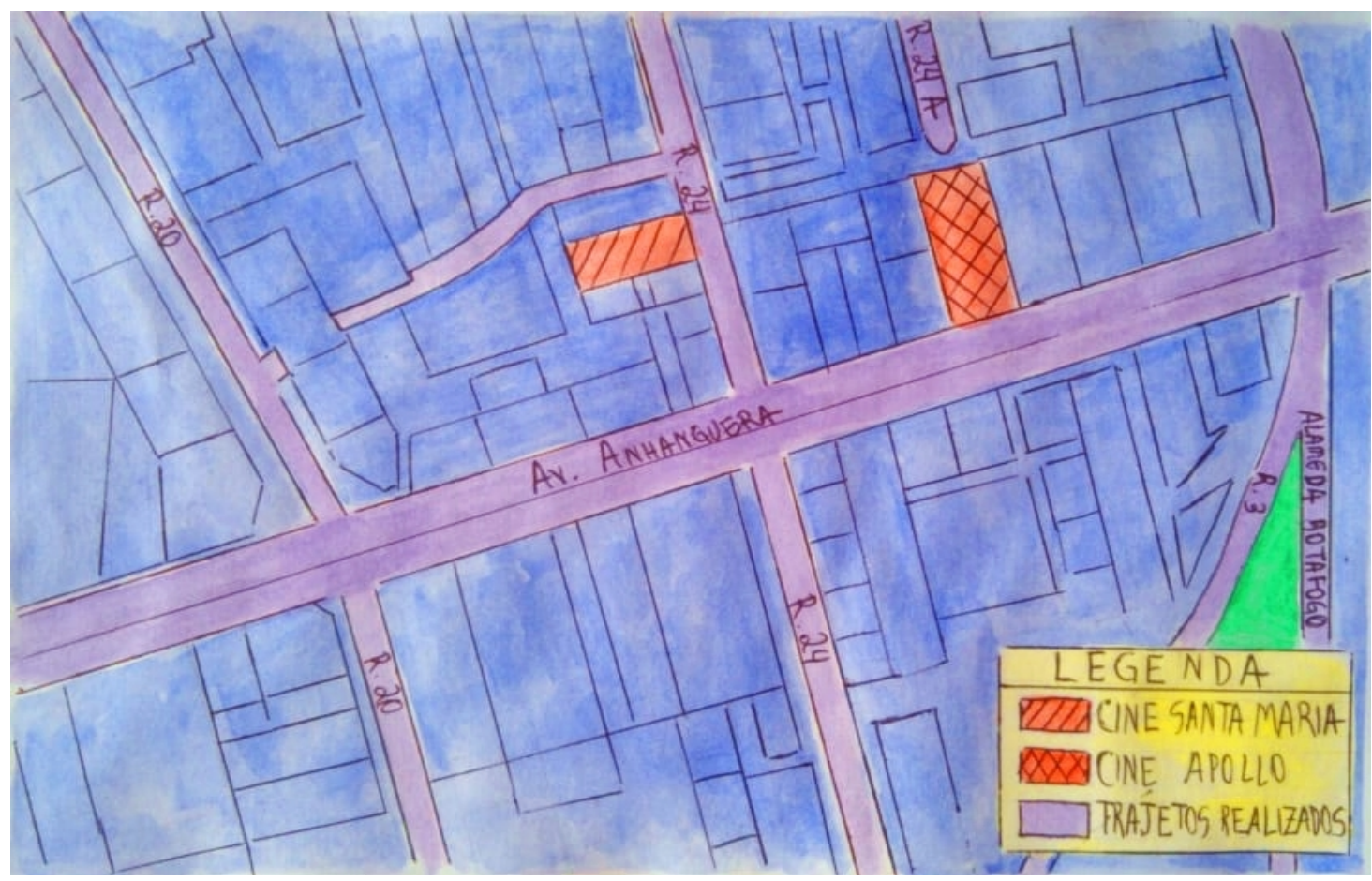

Mapa 2 - Setor Central, Goiânia/GO.

Representação cartográfica dos cinemas adultos. Cine Santa Maria (hachuras diagonais em vermelho), Cine Apollo Show (hachuras cruzadas em vermelho), trajetos realizados (roxo), áreas comerciais e residenciais (azul-escuro) e área arborizada (verde). Diário de campo do autor. 2020.

Iluminuras, Porto Alegre, v. 22, n. 56, p. 321-329, junho, 2021. 


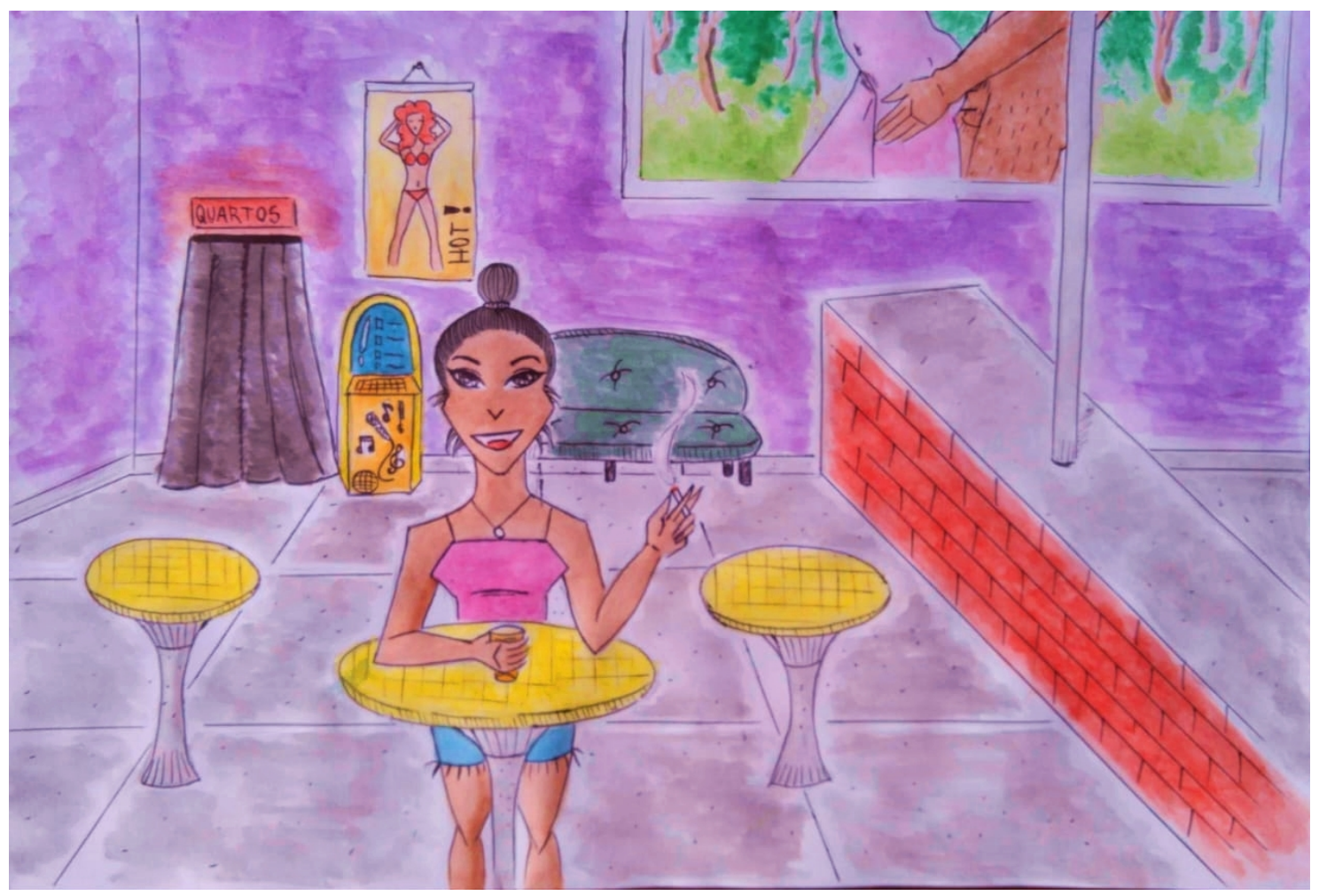

Figura 6. "Compartilhando cervejas e cigarros." Cine Apollo Show, Setor Central, Goiânia/ GO. Cinema adulto e ponto de atuação de mulheres cisgêneras profissionais do sexo. Diário de campo do autor. Noite. 2020.

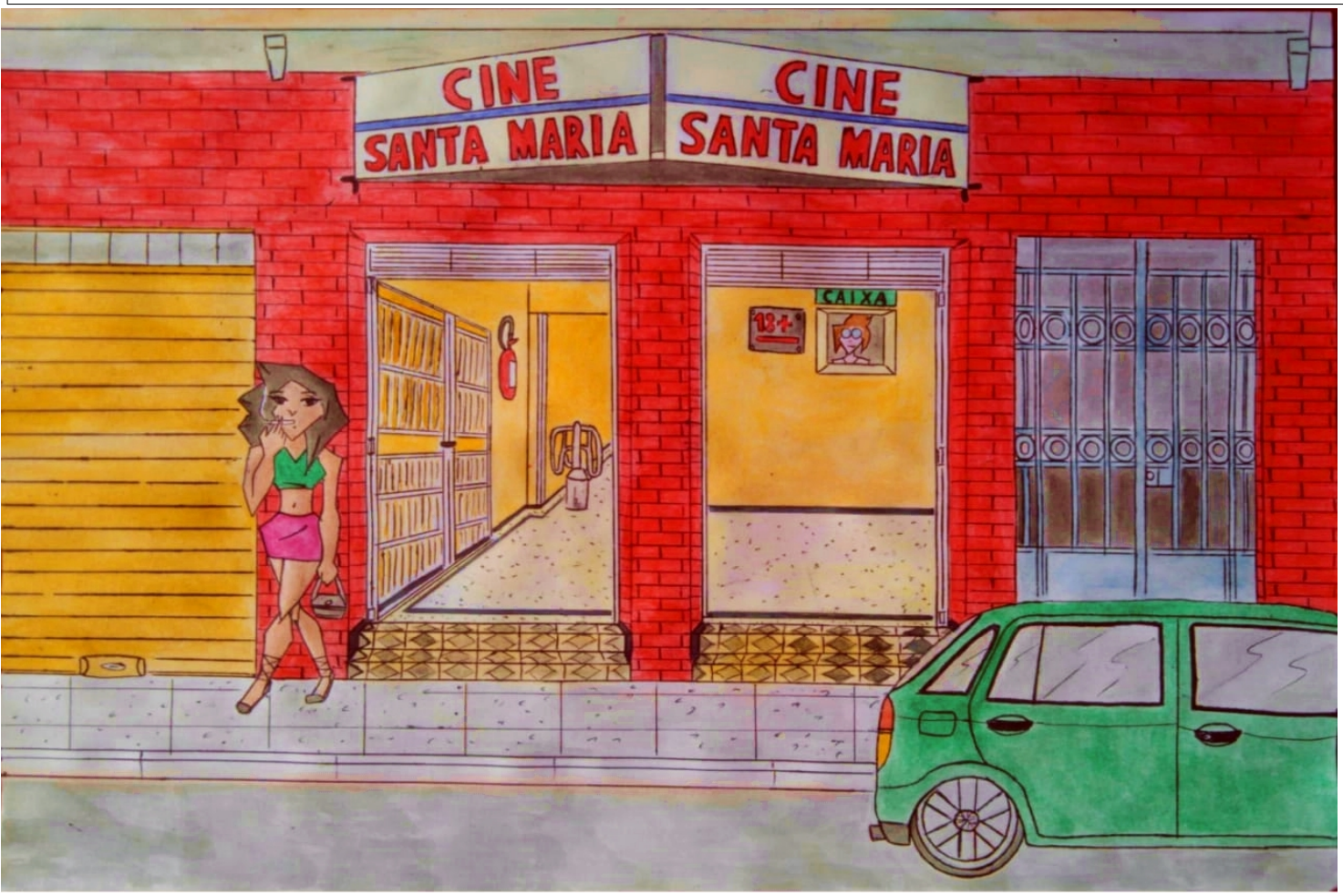

Figura 7. "Observações em frente ao Cine Santa Maria.” Cine Santa Maria, Setor Central, Goiânia/GO. Cinema adulto e ponto de atuação de pessoas travestis profissionais do sexo. Diário de campo do autor. Tarde. 2020. 


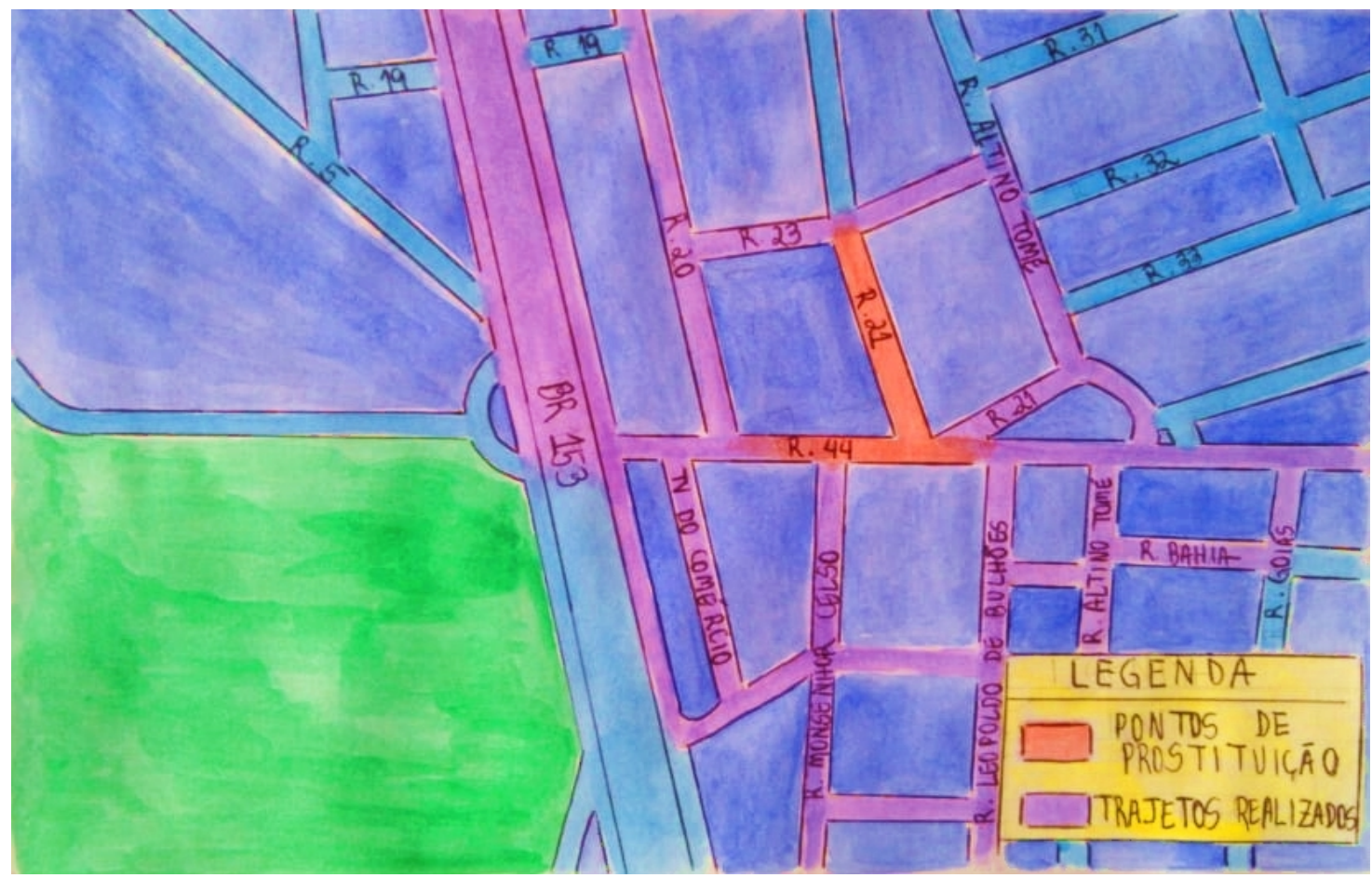

Mapa 3 - Bairro Vila Brasília ("Setor dos Motéis"), Aparecida de Goiânia/GO.

Representação cartográfica da região popularmente conhecida como "Setor dos Motéis". Durante o dia mulheres cisgêneras profissionais do sexo atuam nas ruas 21 e 44, representadas pela cor vermelha.

Durante a noite, pessoas travestis atuam nestes pontos. As observações realizadas encontram-se representadas em roxo, ruas adjacentes em azul-claro, espaços residenciais e comerciais em azul-escuro e áreas arborizadas em verde. Diário de campo do autor. 2020.

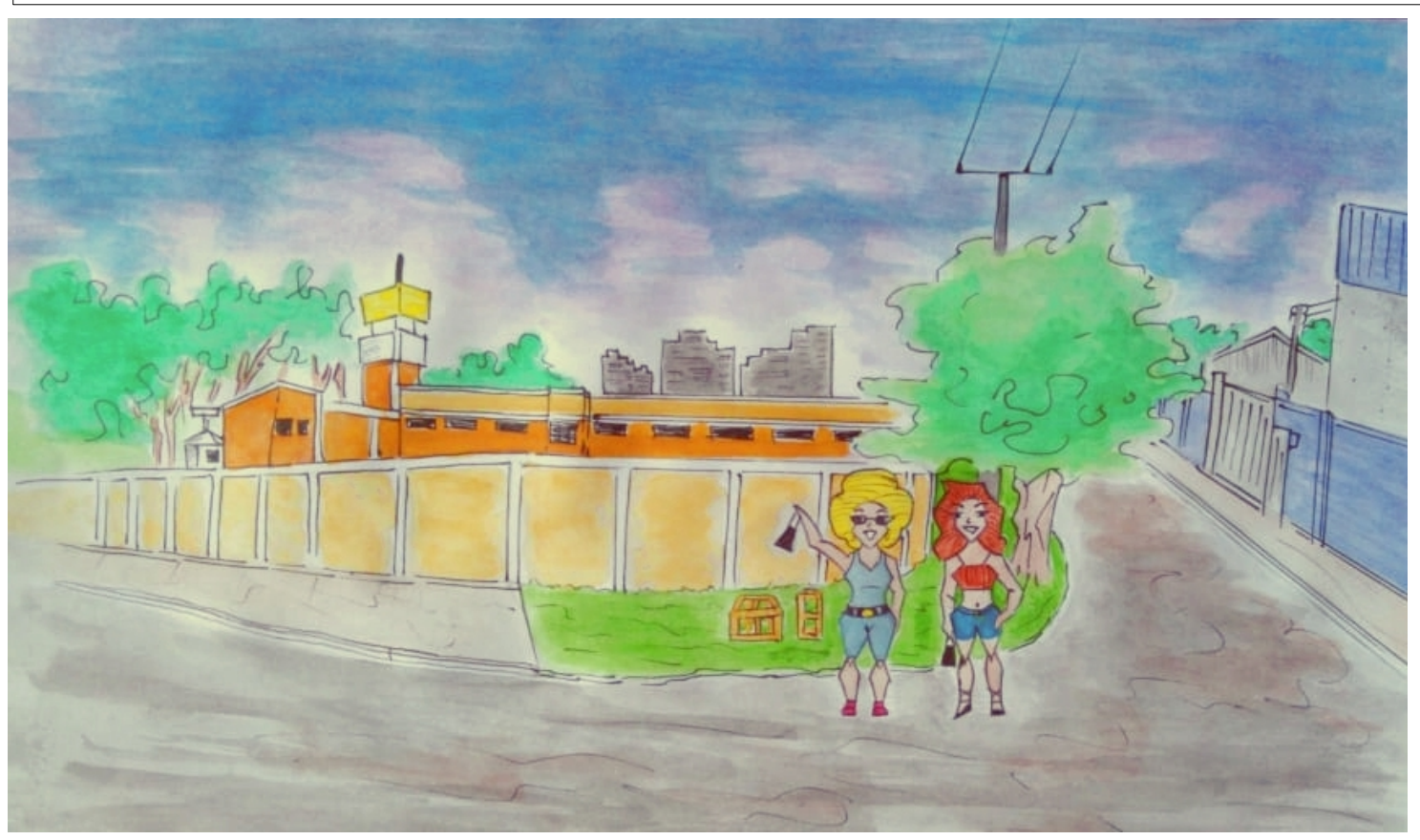

Figura 8. "Profissionais em atuação." Rua 44, esquina com a rua 21, parte lateral de um motel localizado no bairro Vila Brasília, Aparecida de Goiânia/GO. Diário de campo do autor. Manhã. 2019.

Iluminuras, Porto Alegre, v. 22, n. 56, p. 321-329, junho, 2021. 